\title{
Citometria de fluxo no diagnóstico da leishmaniose visceral canina
}

[Flow cytometry used in canine visceral leishmaniasis diagnosis]

\author{
A.V. Carvalho Neta ${ }^{1}$, R.D.R. Rocha ${ }^{2}$, C.M.F. Gontijo ${ }^{3}$, A.B. Reis $^{3}$, O.A. Martins-Filho ${ }^{3}$ \\ ${ }^{1}$ Aluna de pós-graduação EV-UFMG \\ ${ }^{2}$ FIOCRUZ - Rio de Janeiro, RJ \\ ${ }^{3}$ Centro de Pesquisas René Rachou-FIOCRUZ - Belo Horizonte, MG
}

\begin{abstract}
RESUMO
Descreve-se a padronização de nova metodologia para detecção de anticorpos antiformas promastigotas fixadas de $L$. (L.) chagasi, por citometria de fluxo (AAPF-IgG), sua aplicabilidade e desempenho na identificação de casos de leishmaniose visceral canina (LVC). Foram avaliados dois grupos de cães classificados pela reação de imunofluorescência indireta (RIFI), como: não reatores (NR, $n=10)$ e reatores $(\mathrm{R}, \mathrm{n}=50)$ dos quais foram coletadas amostras de sangue (soro) para realização dos testes laboratoriais. Os resultados relacionados ao estabelecimento, aplicabilidade e desempenho da metodologia AAPF-IgG demonstraram que essa metodologia possibilita a identificação de uma região de reatividade diferencial entre cães NR e R, no soro diluído a 1:2048 e o valor de 20\% de parasitos fluorescentes positivos (PPFP) como ponto de corte entre resultados positivos e negativos, mostrando que a AAPF-IgG aplica-se na identificação de casos de LVC, possibilitando distinguir $96 \%$ de cães R como positivos e $100 \%$ de cães NR como negativos. Esses resultados em conjunto sugerem que a utilização da AAPF-IgG pode ser um novo instrumento para ensaios clínicos de diagnóstico sorológico da LVC.
\end{abstract}

Palavras-chave: leishmaniose visceral canina, diagnóstico sorológico, citometria de fluxo, Leishmania chagasi, Leishmania infantum

\begin{abstract}
The current study evaluated the standardization of a new methodology for detection of anti-fixed L. (L.) chagasi promastigote antibodies by flow cytometry (AAPF-IgG), as well its applicability and performance in the identification of cases of Canine Visceral Leishmaniasis (CVL). Two groups of dogs were classified by RIFI (gold standard) as no reactors (NR, $n=10)$ and reactors $(R, n=50)$. Blood samples were collected and used for the laboratorial tests (RIFI and AAPF-IgG). The results showed that the new AAPF-IgG assay makes possible the identification of an area of differential reactivity between dogs $N R$ and $R$ at the dilution of 1:2048 and 20\% of percentage of positive fluorescent parasite as the cut point among positive and negative results. The AAPF-IgG assay was able to distinguish $96 \%$ of $R$ dogs as positive and $100 \%$ of NR dogs as negative. Hence, those data support the applicability of flow cytometry AAPF-IgG method as a new instrument for serological diagnosis of CVL.
\end{abstract}

Keywords: canine visceral leishmaniasis, serologic diagnosis, flow cytometry, Leishmania chagasi, Leishmania infantum.

Recebido em 13 de dezembro de 2004

Aceito em 17de outubro de 2005

E-mail: alcinaven@yahoo.com 


\section{INTRODUÇÃO}

A leishmaniose visceral é uma antropozoonose de distribuição mundial, causada por Leishmania (Leishmania) chagasi ou Leishmania (Leishmania) infantum. O agente é um protozoário da família Tripanossomatidae (Lainson e Shaw, 1978), parasito intracelular obrigatório de células do sistema mononuclear fagocitário (SMF) (De Luna et al., 1999). Assume grande importância devido à elevada taxa de mortalidade dos indivíduos humanos infectados, quando não submetidos ao tratamento, representando, assim, sério problema em saúde pública em vários países (Guerin et al., 2002). A leishmaniose visceral canina, do ponto de vista epidemiológico, é considerada mais importante que a doença humana, pois, além de ser mais prevalente, apresenta grande contingente de animais infectados com parasitismo cutâneo, sintomáticos ou assintomáticos (Cabral et al., 1998), que serve como fonte de infecção para os insetos vetores. Essas características tornam o cão doméstico o principal reservatório do parasito (Ashford, 1996).

As dificuldades na determinação da doença clínica devido à variabilidade das manifestações da infecção direcionam o diagnóstico para os métodos laboratoriais. No entanto, diante de algumas divergências entre os métodos de diagnóstico disponíveis, tem havido busca constante por novos testes mais específicos que garantam que os animais positivos sorologicamente realmente estejam parasitados, possibilitando maior segurança na implementação das ações de controle, dentre elas a eutanásia dos animais positivos.

Considerando que os estudos sorológicos baseados na citometria de fluxo constituem-se um campo com grandes possibilidades de crescimento devido à sensibilidade de detecção aumentada em relação a outros métodos (Martins-Filho et al., 1995), a avaliação da resposta humoral neste trabalho dar-se-á por meio do estudo de imunoglobulinas (IgG total) quanto à reatividade dos anticorpos que se ligam a formas promastigotas fixadas de Leishmania (L.) chagasi por citometria de fluxo (AAPFIgG). Tal estudo permitirá ampliar o conhecimento desses eventos imunológicos, tendo em vista que esse sistema (AAPF-IgG) é isento de variabilidades metodológicas inerentes ao analista e com sensibilidade e especificidade muito superiores aos diferentes protocolos de detecção e revelação convencionais e poderá trazer novas perspectivas para os estudos sorológicos aplicados ao diagnóstico, prognóstico, controle pós-vacinal e acompanhamento de protocolos terapêuticos convencionais ou experimentais da LVC.

\section{MATERIAL E MÉTODOS}

A pesquisa foi realizada no município de Belo Horizonte com cães recolhidos de áreas endêmicas com alta prevalência de casos humanos de leishmaniose visceral nos últimos anos, de acordo com dados fornecidos pela Secretaria Municipal de Saúde de Belo Horizonte (SMS/BH).

O critério de escolha e inclusão dos cães na pesquisa baseou-se nos resultados da reação de imunofluorescência indireta (RIFI) com base nas normas do Ministério da Agricultura Pecuária e Abastecimento e Ministério da Saúde pois o RIFI e o ELISA, são os métodos utilizados para classificação dos animais em reatores $(\mathrm{R})$ e não reatores (NR).

Foram selecionados 60 cães para a amostra experimental, classificados em dois grupos: grupo 1 (controle) - 10 cães sadios e sorologicamente negativos pela RIFI (NR); grupo 2 - 50 sorologicamente positivos à RIFI (R).

O sangue foi coletado da veia cefálica, após desinfecção do local, tricotomia e assepsia com álcool iodado a $70 \%$, conforme as recomendações do Colégio Brasileiro de Animais de Experimentação (COBEA), e em concordância com a Lei ${ }^{\circ}$. 6.638 , de 8 de maio de 1979, que estabelece normas práticas didático-científicas de conduta de pesquisa em animais. As amostras de sangue de cada animal foram dessoradas, e os soros inativados a $56^{\circ} \mathrm{C}$ por 30 minutos. Em seguida, foram centrifugadas a $14.000 \mathrm{rpm}$ a $18^{\circ} \mathrm{C}$ por 5 minutos para remoção de partículas; após a centrifugação, o sobrenadante foi aliquotado e estocado a $-20^{\circ} \mathrm{C}$ até sua utilização nos testes sorológicos. 
A RIFI foi realizada no laboratório de leishmanioses $^{1}$ de acordo com metodologia padronizada $^{2}$ (Camargo e Rebonato, 1969). Os resultados foram expressos como positivos até a última diluição em que se observou a fluorescência. Com base nas normas do Ministério da Saúde do Brasil, todos os cães que apresentaram títulos iguais ou superiores a 1:40 foram considerados positivos ou reatores.

Foi utilizada a cepa MHOM/BR/1972/BH46³ de Leishmania (L.) chagasi isolada de caso humano e mantida pelo Laboratório de Leishmaniose do Centro de Pesquisas René Rachou (FIOCRUZ$\mathrm{MG})$.

As formas promastigotas vivas de $L$. (L.) chagasi foram cultivadas em erlenmeyers contendo meio ágar-sangue, novy-mac-neal-nicolle (NNN) associado ao liver infusion tryptose (LIT). As culturas foram mantidas em estufa a $24 \pm 1{ }^{\circ} \mathrm{C}$. A cada quatro dias, as culturas eram examinadas quanto à motilidade, morfologia e ausência de contaminação, sendo os parasitos periodicamente re-inoculados pela transferência de $1,0 \times 10^{6}$ promastigotas $/ \mathrm{ml}$ para outros erlenmeyers contendo NNN-LIT. No meio contendo apenas LIT, os parasitos foram incubados por um período de 10 dias de cultivo para serem utilizados nos experimentos de reação de imunofluorescência indireta por citometria de fluxo.

Os parasitos com 10 dias de cultivo em LIT foram transferidos para tubos de polipropileno de $50 \mathrm{ml}$ (Falcon), homogeneizados em vórtex à baixa rotação (rotação 4) para desfazer os grumos. Em seguida, a suspensão foi submetida a uma centrifugação diferencial $\left(25^{\circ} \mathrm{C}, 200 \mathrm{rpm}\right.$ por 10 minutos) para remoção de contaminantes como possíveis grumos de parasitas remanescentes que foram removidos no sedimento. A suspensão de parasitos no sobrenadante foi deixada em repouso por 10 minutos à temperatura ambiente, para maximizar a recuperação dos parasitos no sobrenadante. $\mathrm{O}$ sobrenadante foi, então, transferido para outro tubo de polipropileno de $50 \mathrm{ml}$ e o sedimento foi desprezado. Em seguida, os parasitos foram

\footnotetext{
1 Centro de Pesquisas René Rachou/FIOCRUZ - Belo Horizonte, $\mathrm{MG}$

${ }^{2}$ Biomanguinhos/FIOCRUZ Rio de Janeiro, RJ

3 Departamento de Parasitologia - ICB-UFMG, Belo Horizonte, MG
}

lavados em solução salina tamponada (PBS) contendo $10 \%$ de soro fetal bovino (SFB), por duas vezes, por centrifugação a $4^{\circ} \mathrm{C}$ (2200rpm por 10 minutos). Os aspectos morfométricos das formas promastigotas de $L$. $(L)$. chagasi foram estimados, por citometria de fluxo, de forma a apresentar uma distribuição homogênea em gráficos de tamanho versus granulosidade (Figura 1-A). Após essa etapa, os parasitos foram fixados com solução fixadora $(10,0 \mathrm{~g} / 1 \mathrm{de}$ paraformaldeído, 10,2g/1 de cacodilato de sódio e $6,65 \mathrm{~g} / 1$ de cloreto de sódio, $\mathrm{pH} 7,2-7,4)$ e armazenados a $4^{\circ} \mathrm{C}$ por, no mínimo, 30 minutos até o momento de uso. Ao final das etapas de fixação, procedia-se à contagem do número de parasitos, e a suspensão celular era ajustada para aproximadamente $5 \times 10^{6}$ promastigotas $/ \mathrm{ml}$. Os parasitos fixados foram armazenados a $4^{\circ} \mathrm{C}$ e utilizados dentro do período máximo de 1 mês.

As amostras de soros diluídos inicialmente 1:128 em PBS suplementado com 3\% SFB. Para os ensaios de citometria de fluxo, foram usadas microplacas de 96 poços de fundo em "U", nos quais foram adicionados $50 \mu \mathrm{l}$ dos soros nas

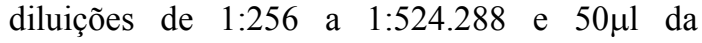
suspensão de parasitos fixados. A mistura foi incubada a $37^{\circ} \mathrm{C}$ por 30 minutos, lavada duas vezes com $150 \mu$ de $\mathrm{PBS}-\mathrm{SBF}$ por centrifugação (2.200rpm, $\left.4^{\circ} \mathrm{C}, 10 \mathrm{~min}\right)$, e o sobrenadante desprezado. Para revelação da ligação de $\operatorname{IgG}$ na superfície do parasito, procedeu-se à incubação, ao abrigo da luz, das formas promastigotas fixadas, na presença de $50 \mu \mathrm{l}$ de anticorpo policlonal anti-IgG canino (específico para a porção Fc) marcado com isotiocianato de fluoresceína-FITC nas diluições (1:500, 1:1000 e 1:2000 em PBS-SFB) a $37^{\circ} \mathrm{C}$ por 30 minutos. Decorrido o tempo de incubação com o conjugado, os parasitos foram lavados novamente duas vezes com $150 \mu$ de PBS-SBF por centrifugação $\left(4^{\circ} \mathrm{C}, 2200 \mathrm{rpm}\right.$ por $\left.10 \mathrm{~min}\right)$, e o sobrenadante desprezado. Em seguida, os parasitos foram fixados e mantidos a $4^{\circ} \mathrm{C}$, ao abrigo da luz até o momento da leitura no citômetro de fluxo.

A leitura dos experimentos de imunofluorescência por citometria de fluxo foi realizada no citômetro de fluxo ${ }^{4}$ que permitiu ajustar o número de eventos celulares para

\footnotetext{
${ }^{4}$ FACScalibur - BECTON DICKINSON, San Jose, EUA
} 
10.000 parasitos/segundo em uma análise automatizada de três parâmetros celulares: tamanho (determinado pela difração do raio laser - "Forward scatter" - FSC), granulosidade ou complexidade interna (determinada pela refração e reflexão do raio laser - "Side Scatter" - SSC) e intensidade relativa de fluorescência (FL1), sendo ainda utilizado um sistema de computador contendo o "Software - CELLQuest", para aquisição, armazenamento e análise imediata ou posterior dos dados referentes ao material estudado.

A análise da reatividade de anticorpos anti- $L$. (L.) chagasi foi feita inicialmente pela seleção da população celular de interesse (Figura 1A). Dessa forma, o perfil foi obtido ajustando-se os ganhos de tamanho e granulosidade, em escala
LOG, com valores E00 e 300, respectivamente. Os resultados das análises de fluorescência foram expressos sob a forma de percentual de parasitos fluorescentes positivos (PPFP) observados para cada teste individual em relação ao controle do conjugado. O PPFP foi determinado para cada amostra por limiar de negatividade em função da curva de fluorescência obtida para o controle da ligação inespecífica do conjugado (M1, Figura 1B). Para cada experimento, estabeleceu-se um limiar de reatividade de no máximo $2 \%$ de PPFP para o controle do conjugado. Em seguida, empregando o mesmo marcador, foram obtidos os valores de PPFP para amostras individuais (Figuras $1 \mathrm{C} \mathrm{e}$ 1D). Para cada conjunto de ensaios, um novo marcador foi posicionado, empregando o controle do conjugado daquele experimento.

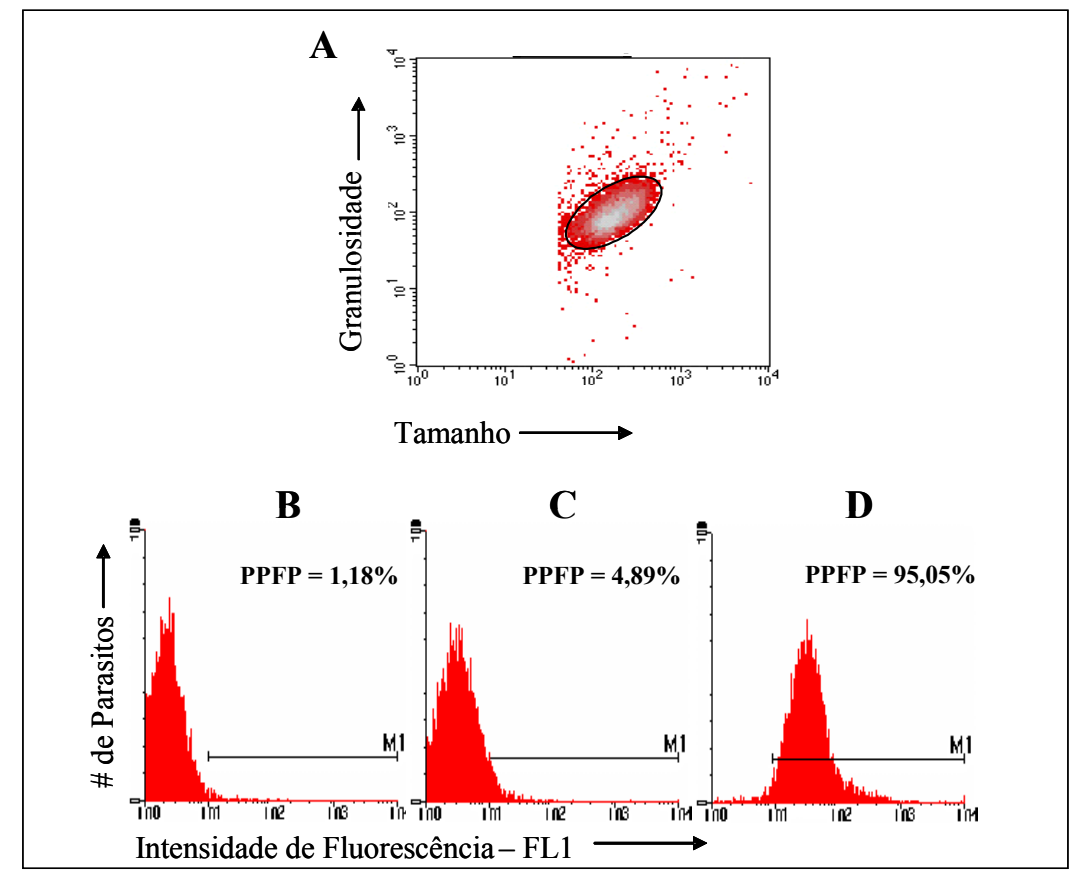

Figura 1. Representação esquemática da seqüência das análises dos dados obtidos por citometria de fluxo. (A) Seleção da população de formas promastigotas de L. (L.) chagasi; (B) Histograma individual representando o percentual de parasitos fluorescentes (PPFP) obtidos com controle interno da reação; (C) após a incubação com um soro de um cão NR; e (D) após incubação com um soro de um cão R. O posicionamento do marcador (M1) segue sempre o critério de se obter no máximo 2\% de PPFP para o controle do conjugado. 
A análise dos resultados foi realizada segundo Martins-Filho et al. (1995), que consideraram negativos os animais com valores de PPFP $\leq 20 \%$ e positivos os animais que apresentassem valores de $\mathrm{PPFP}>20 \%$. Na padronização da metodologia, os valores de PPFP foram classificados em positivo ou negativo para cada diluição da mistura de soros. $\mathrm{Na}$ análise do método, em que foram avaliados os soros individuais, os valores de PPFP foram classificados em positivo ou negativo considerando cada animal avaliado.

A analise estatística foi realizada utilizando o software MedCalc ${ }^{5}$, por meio do qual foram determinados: a acurácia, o ponto de corte do método avaliado através da receiver operating characteristic (curva ROC) e os índices de desempenho do método: sensibilidade, especificidade, valor preditivo positivo e negativo, índice $\mathrm{J}$ de Youden e razões de verossimilhança.

\section{RESULTADOS E DISCUSSÃO}

$\mathrm{Na}$ etapa inicial de padronização, a escolha de variáveis, tais como: fase de cultivo das formas promastigotas (10 dias - fase estacionária de crescimento), o número de parasitos em suspensão $\left(5,0 \quad\right.$ x $\quad 10^{6}$ parasitos $\left./ \mathrm{mL}\right), \quad$ a temperatura e tempo de reação $\left(37^{\circ} \mathrm{C}\right.$ por $30 \mathrm{~min}$ ), baseou-se nas condições descritas por Rocha et al. (2002) para pesquisa de anticorpos humanos anti-L.. (Viania). braziliensis. No presente estudo, buscou-se a concentração ideal do anticorpo anti-Fc de $\operatorname{IgG}$ canino e a concentração ideal do soro canino capaz de discriminar cães $\mathrm{R}$ de cães $\mathrm{NR}$, em que foram empregadas as diluições 1:500, 1:1000 e 1:2000.

Empregando o critério descrito por MartinsFilho et al. (1995), a análise dos resultados mostrou curvas de titulação de anticorpos que configuram a alta sensibilidade do teste. Os resultados da pesquisa AAPF-IgG das misturas de soros de cães R mostram valores de PPFP positivos até a diluição 1:32.768 para as três diluições do conjugado empregadas (Figuras 2 A, B e C). Já as misturas de soros NR apresentaram valores de PPFP positivos até a

${ }^{5}$ Microsoft, Mariakerk, Belgium diluição 1:2.048, 1:1024 para as diluições do conjugado 1:500 e 1:1000, respectivamente (Figuras 2 A e B) e iniciam com valores de PPFP negativos para a diluição do conjugado 1:2000 (Figura 2 C).

Esses resultados possibilitaram a identificação de uma região de reatividade $(\mathrm{R})$ diferencial entre cães NR (valor de $P P F P \leq 20 \%$ ) e cães $R$ (valor de PPFP $>20 \%$ ). Este perfil de reatividade diferencial foi observado no ponto de diluição da mistura de soros, de 1: 4.096, 1:2048 e 1:256 para as diluições do conjugado 1:500, 1:1000 e 1:2000, respectivamente. Em todas as diluições do conjugado empregadas, foram demonstradas reatividades sorológicas diferenciais entre cães $R$ e cães NR, no entanto a análise dos resultados conduziu a escolha da diluição do conjugado 1:1000, sendo a melhor diluição que associou boa sensibilidade do método com uma especificidade alcançada em títulos menores.

A opção em favorecer a sensibilidade baseou-se no fato de que a pesquisa AAPF-IgG foi testada em misturas de soros, para aplicação em amostras de soros individuais, e no fato de que possivelmente existam soros com baixos títulos de anticorpos, os quais poderiam não ser detectáveis em diluições maiores do conjugado, como a diluição 1:2000. Esse tipo de abordagem encontra suporte nos estudos desenvolvidos por Rocha et al. (2002), que preconizam a utilização de um método mais sensível na pesquisa de anticorpos por citometria de fluxo, no âmbito da leishmaniose tegumentar americana (LTA). Nesse contexto, um método com maior sensibilidade poderia favorecer inclusive a prática de controle de cura, oferecendo suporte pós-terapêutico precoce, considerando a baixa sensibilidade dos métodos de pesquisa direta de parasito ou de produtos derivados em espécimes biológicas. Desta forma, a análise dos resultados da etapa de padronização sugeriu a pesquisa de AAPF-IgG como um novo método de diagnóstico da LVC capaz de diferenciar cães $\mathrm{R}$ de cães NR.

A análise das curvas de titulação dos anticorpos dos soros individuais permitiu confirmar que a região de reatividade $(\mathrm{R}=1: 2048)$ corresponde ao primeiro título de reação diferencial entre cães NR (PPFP $\leq 20 \%)$ e cães R (PPFP $>20 \%)$ (Figuras 3 A e B). 


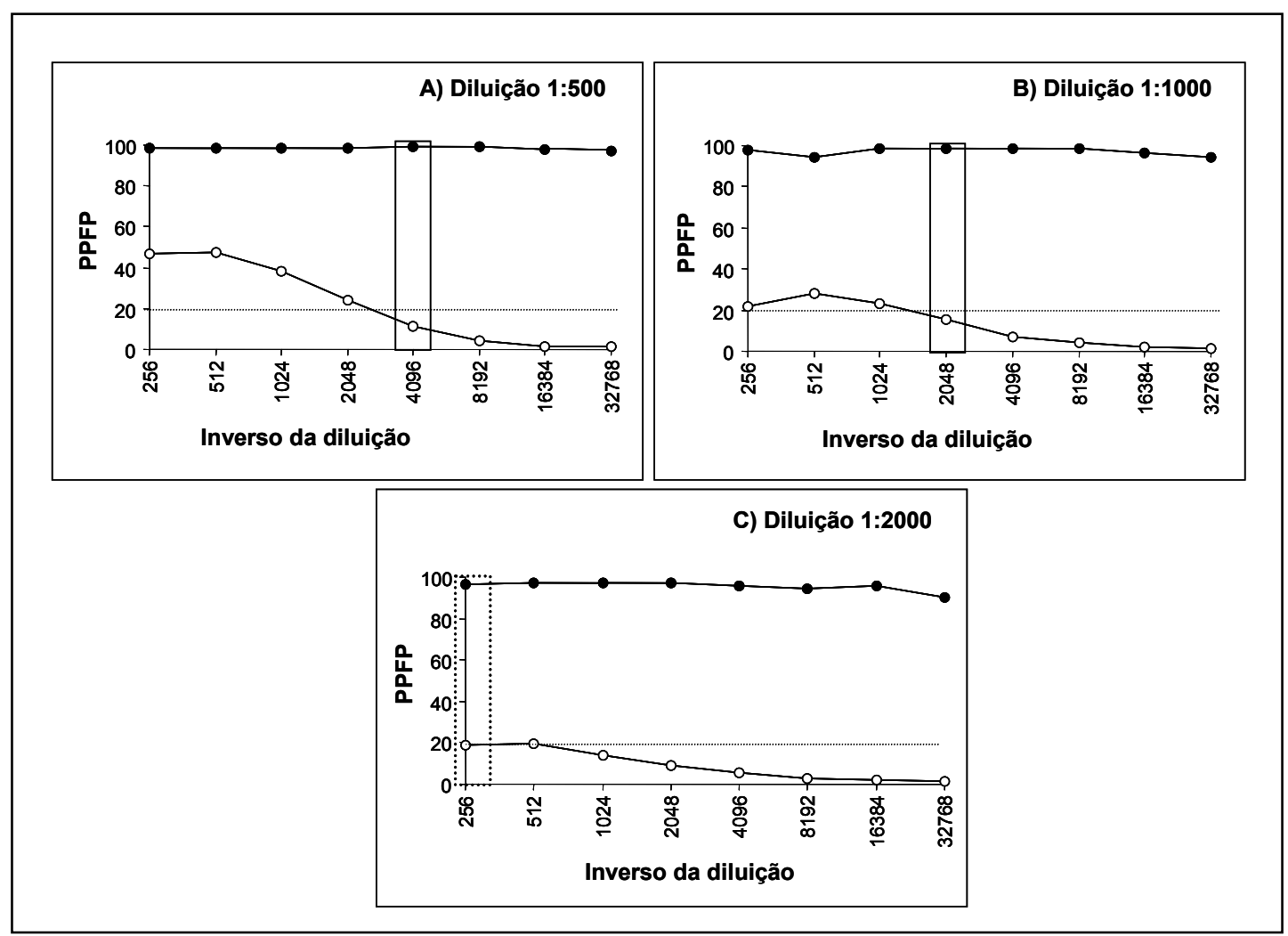

Figura 2. Curvas de titulação de anticorpos IgG antiformas promastigotas fixadas de L. (L.) chagasi, presentes em misturas de soros de cães com reação de imunofluorescência indireta (RIFI) positiva R (linha com círculo preenchido) ou negativa NR (linha com círculo sem preenchimento) para leishmaniose visceral canina (LVC). Os resultados de reatividade de cada grupo estão expressos como percentual de parasitos fluorescentes positivos (PPFP), empregando o valor de $20 \%$ (linha pontilhada) como ponto de corte entre resultados positivos (PPFP $>20 \%$ ) e negativos ( $\mathrm{PPFP} \leq 20 \%$ ). Os retângulos presentes nos gráficos $\mathrm{A}, \mathrm{B}$ e $\mathrm{C}$ representam a primeira diluição do soro, na qual foi possível diferenciar as misturas de soros R e NR.

Adicionalmente, as figuras 3 e 4 demonstram que, na diluição de 1:2048, os soros reatores pela RIFI para LVC estavam relacionados a valores de PPFP de alta reatividade na citometria de fluxo com 96\% destes caracterizados como positivos, e os soros não reatores relacionados a valores de PPFP de baixa reatividade, com $100 \%$ dos cães deste grupo caracterizados como negativos. Estes resultados indicam que, ao se empregar o critério de estabelecimento de um ponto de corte de $20 \%$ de PPFP, o estudo de amostras individuais demonstrou que a pesquisa de AAPF-IgG aplica-se à identificação de animais positivos para LVC, uma vez que permitiu distinguir $96 \%$ (48/50) dos cães R como positivos (PPFP $>20 \%$ ) e $100 \%(10 / 10)$ dos cães NR como negativos $(\mathrm{PPFP} \leq 20)$. 


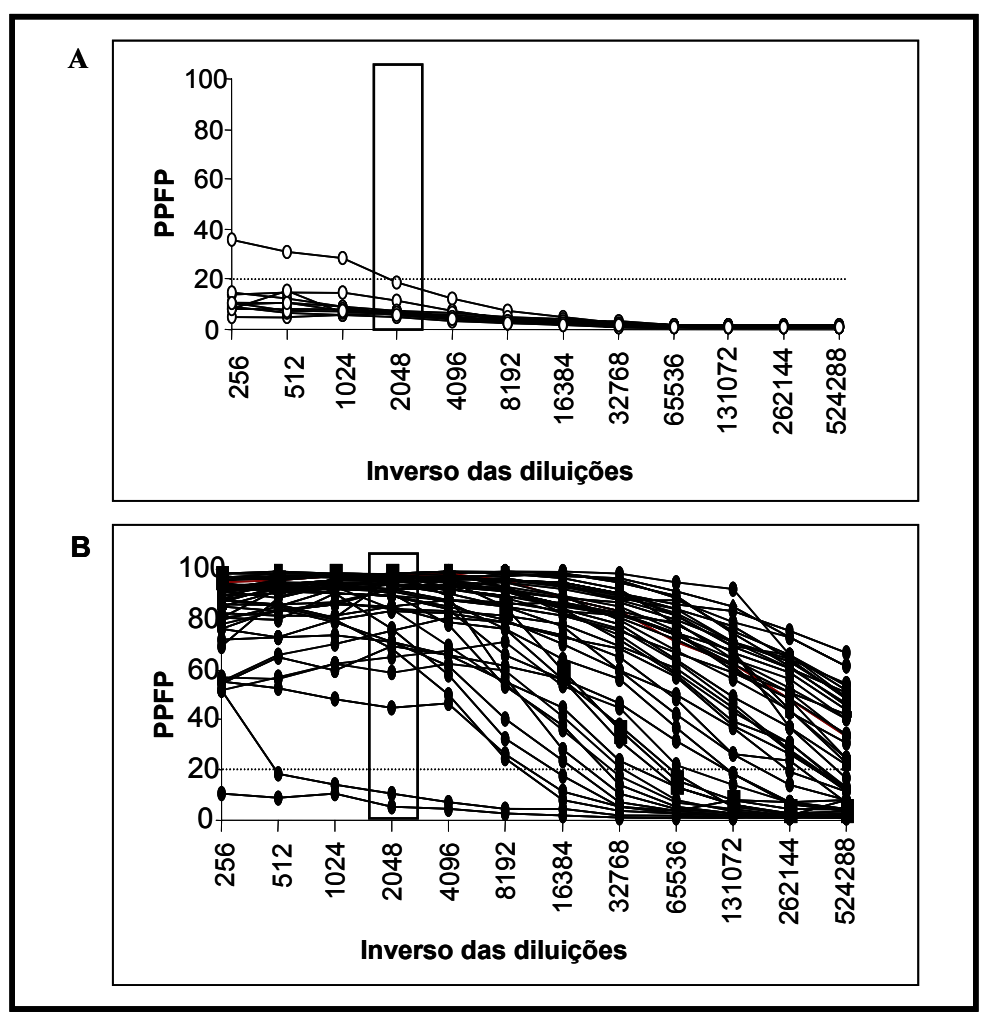

Figura 3. Reatividade de IgG antiformas promastigotas fixadas de $L$. (L.) chagasi em soros individuais de cães do grupo NR (A) e do grupo R (B). O resultado da reatividade de IgG para cada amostra individual está expresso como PPFP, empregando o valor de 20\% (linha pontilhada) como ponto de corte entre resultados positivos (PPFP $>20 \%$ ) e negativos ( $\mathrm{PPFP} \leq 20 \%$ ). Os retângulos representam a primeira diluição do soro 1:2048, empregada no critério de diferenciação das misturas de soros NR e R.

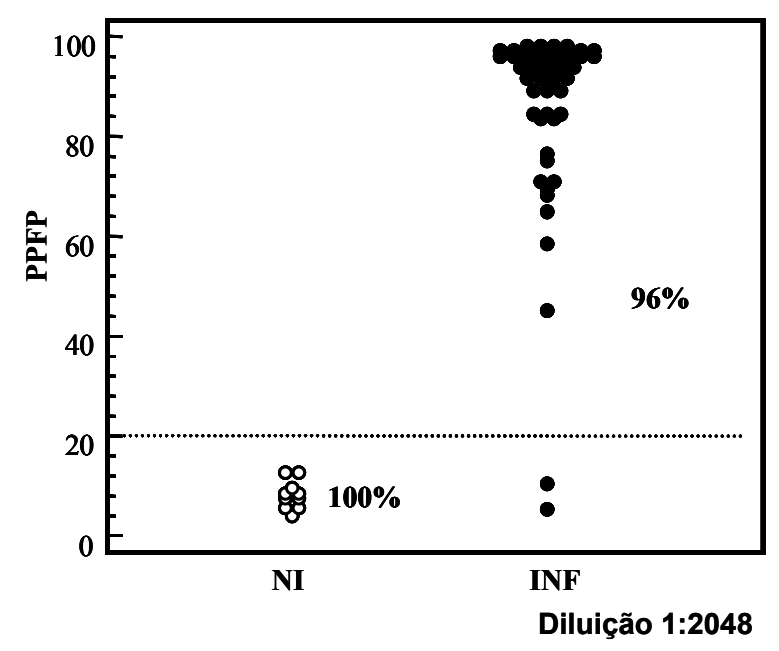

Figura 4. Reatividade de IgG antiformas promastigotas de L. (L.) chagasi em soros individuais de cães NR e R, na diluição de 1:2048. 
Cabe aqui ressaltar que os dois cães do grupo de infectados que apresentaram valores de PPFP $\leq 20 \%$ possuíam títulos da RIFI de 1:40. Neste contexto, Haas et al. (1988) descrevem que a diluição padrão (1:40) para determinação de animais positivos deve ser reavaliada, visto que, anualmente, cerca de 25.000 cães são sacrificados sem que haja uma comprovação segura de que eles tenham contraído a infecção.

A avaliação dos resultados da etapa de análise do método sugeriram a aplicabilidade da pesquisa de AAPF-IgG ao diagnóstico da LVC, reforçando a utilização do ponto de corte previamente descrito e o ponto de reatividade diferencial determinada $(1 / 2048)$

Para avaliação do desempenho da nova metodologia proposta, foi construída a curva
ROC e calculados os índices de desempenho de testes de diagnósticos, expressos em porcentagem e em chance.

O estudo da curva ROC (Figura 5) na AAPFIgG demonstrou que o valor da área sobre a curva (ASC) da AAPF-IgG (ASC=0,98; $\mathrm{IC}_{95 \%}=$ 0,90-0,99) indica uma elevada acurácia do teste. Além disto, o estudo da curva ROC da AAPFIgG confirmou que o valor de $20 \%$ de PPFP seria um melhor ponto de corte para a segregação dos grupos NR e R. O estabelecimento desse ponto de corte mostrou uma sensibilidade de $96 \%\left(\mathrm{IC}_{95 \%}=86,3-99,4\right) \mathrm{e}$ especificidade de $100 \%\left(\mathrm{IC}_{95 \%}=100,0-100,0\right)$ para a AAPV-IgG, confirmando a habilidade do método no diagnóstico da LVC.

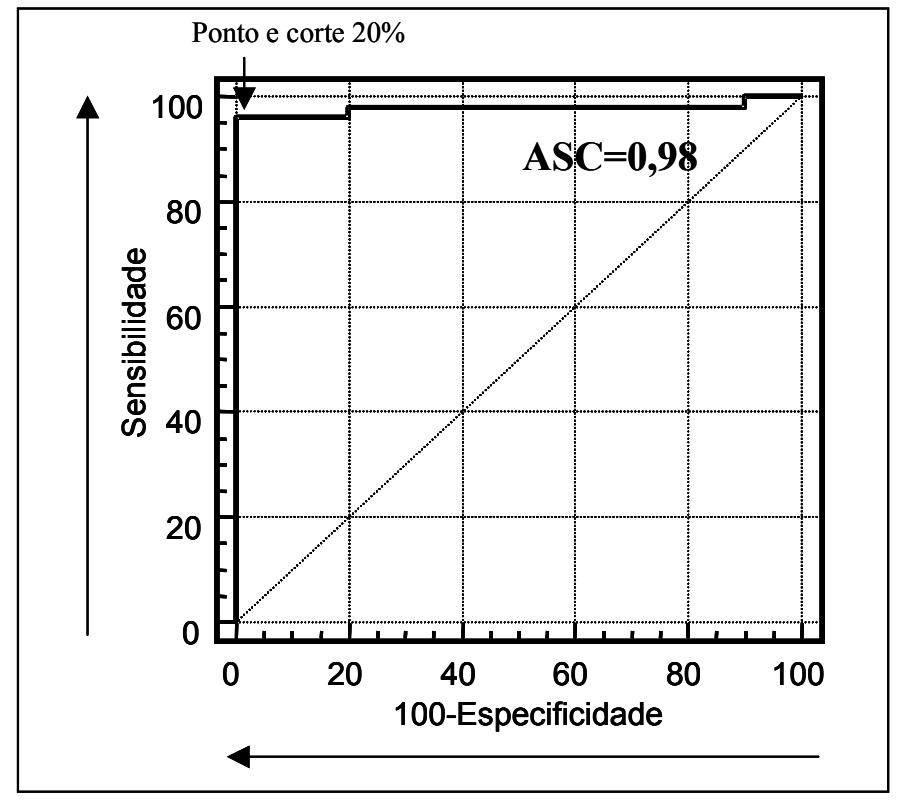

Figura 5. Curva ROC (receiver operating characteristic) da pesquisa de AAPF-IgG, construída a partir dos índices de desempenho, sensibilidade e (1 - Especificidade) do teste avaliado. Os resultados estão expressos pelos pontos dos gráficos, que representam os valores dos referidos índices avaliados, determinando, assim, a área sobre o gráfico (área sobre a curva-ASC $=0,98$ ). A seta representa o melhor ponto de corte sugerido pela curva $(20 \%)$.

As Tab. 1 e 2 resumem as informações referentes aos índices de desempenho da AAPFIgG, com os seus respectivos intervalos de confiança a 95\%. Estes resultados apontam o bom desempenho do método avaliado por meio de indicadores expressos em percentual e em chance, demonstrando que valores de PPFP $>20 \%$ contribuem para a confirmação do diagnóstico sorológico da LVC e que valores de PPFP $\leq 20 \%$ praticamente excluem o diagnóstico sorológico de LVC. 
Tabela 1. Sensibilidade, especificidade, valores preditivos, probabilidade de doença pós-teste negativo, acurácia e índice de Youden da Pesquisa AAPF-IgG, com seus respectivos intervalos de confiança a $95 \%$

\begin{tabular}{lcc}
\multicolumn{1}{c}{ Índice } & Valor (\%) & IC 95\% (\%) \\
\hline Sensibilidade & 96,0 & $86,3-99,4$ \\
Especificidade & 100,0 & $100,0-100,0$ \\
Valor preditivo positivo* $^{*}$ & 91,43 & $0,90-0,99$ \\
Valor preditivo negativo* $^{*}$ & 99,5 & $0,64-0,93$ \\
Acurácia & 96,0 & $0,86-0,99$ \\
İndice J de Youden & 83,0 & $0,71-0,91$ \\
\hline
\end{tabular}

* Prevalência estimada de $10 \%$.

Tabela 2. Razões de verossimilhança (RV) e probabilidades pós-teste (PPT) da pesquisa de anticorpos antiformas promastigotas fixadas AAPF-IgG, na diluição do soro 1:2048 e ponto de corte $20 \%$

\begin{tabular}{cc}
\hline $\begin{array}{c}\text { Faixas de valores de } \\
\text { PPFP }\end{array}$ & $\begin{array}{c}\text { RV e (PPT) para os } \\
\text { resultados da AAPF-IgG }\end{array}$ \\
\hline$>20 \%$ & $>10,0(98 \%)$ \\
$\leq 20 \%$ & $0,04(15 \%)$ \\
\hline
\end{tabular}

Com os resultados obtidos nesse estudo, foi possível estabelecer uma nova metodologia sorológica que utiliza a citometria de fluxo na detecção de anticorpos antipromastigotas de $L$. (L.) chagasi. Esta metodologia demonstrou ser uma alternativa diagnóstica aplicada em estudos de processos imunológicos e imunopatológicos envolvidos na LVC. As informações geradas nesse estudo abrem novas perspectivas para pesquisa sorológica na LVC e estimulam sua continuidade por meio da avaliação da reatividade cruzada com outros organismos e da avaliação de classes de $\operatorname{Ig}(\operatorname{IgA}$ e $\operatorname{IgE}$ ) e subclasses de IgG em diferentes formas clínicas da doença, cães vacinados ou em tratamento. Além disso, a elaboração de outros estudos nesta linha poderá contribuir na elucidação das dúvidas e no entendimento da resposta imune humoral em cães.

\section{REFERÊNCIAS BIBLIOGRÁFICAS}

ASHFORD, R.W. Leishmaniasis reservoirs and their significance in control. Clinic in Dermatology, v.14, p.523-532, 1996.

CABRAL, M., O'GRADY, J.E., GOMES, S., SOUSA, J.C., THOMPSON, H. \& ALEXANDER, J. The immunology of canine leishmaniasis: strong evidence of a developing disease spectrum from asymptomatic dogs. Veterinary Parasitology, v.76, p.173-180, 1998.

CAMARGO, M. E. \& REBONATO, C. Cross reactivity in immunofluorescense for Trypanossoma and Leishmania antibodies. American Journal of Tropical Medicine and Hygiene. v.18, p.500 - 505, 1969.

DE LUNA, R.; VENOTTO, M.L.; IELPO, M.T.; AMBROSIO, R.; PIANTEDOSI, D.L.; MOSCATIELLO, V.; CEARAMELLA, P.; SCALONE, A.; GRADONI, L. MANCINO, D. Early supresión of lymphoproliferative response in dogs with natural infection by Leishmania infantum. Vet. Immunol. Immunopathol., v.70, p.95-103, 1999.

GUERIN, P.J.; OLLIARO, P.; SUNDAR, S.; BOELAERT, M.; CROFT, S.L.; DESJEUX, P.; WASUNNA, M.K.; BRYCESON, A.D.M. Visceral leishmaniasis: current status of control, diagnosis, and treatment, and a proposed research and development agenda. Infectious Disease. v.2, 2002.

HAAS, P.; OZON, C.; BAYADA, M. Expression standartdisée des resultats dans la sérologie de la leishmaniose canine. application a la réaction d'ELISA. Pratique Médicale $e$ chirurgicale de l'Animal de Compagnie, n. 5 (sup), p.89-92, 1988.

LAINSON, R.; SHAW, J. J. Epidemiology and ecology leishmaniasis in Latin America. Nature. v.273, p.595-600, 1978.

MARTINS-FILHO, O.A.; PEREIRA, M.E.S.; CARVALHO, J.F.; CANÇADO, J.R.; BRENER, Z. Flow cytometry, a new approach to detect anti-live trypomastigote antibodies and monitor the efficacy treatment in human chagas disease. Clinical and Diagnostic Laboratory Immunology, v.2, p.569-573, 1995.

ROCHA, R.D.R.; GONTIJO, C.M.F.; ELÓISANTOS, S.M.; CARVALHO, A.T.; CORREAAOLIVEIRA, R.; MARQUES, M.J.; GENARO, O.; MAYRINK, W.; MARTINS-FILHO, O.A. Anticorpos antipromastigotas vivas de Leishmania (Viannia) braziliensis, detectados pela citometria de fluxo, para identificação da infecção ativa na leishmaniose tegumentar americana. Revista da Sociedade Brasileira de Medicina Tropical. v.35, p. 551-562, 2002. 